\title{
UGANDA'S SUCCESSFUL GUINEA WORM ERADICATION PROGRAM
}

\author{
JOHN B. RWAKIMARI, DONALD R. HOPKINS,* AND ERNESTO RUIZ-TIBEN \\ Ministry of Health, Entebbe, Uganda; The Carter Center, Atlanta, Georgia
}

\begin{abstract}
Having begun its national Guinea Worm Eradication Program (UGWEP) in 1991 (1991 population, 16.6 million) with the third-highest number of cases reported by any endemic country, and ranked as the second-highest endemic country in the world in 1993, by 2004, Uganda celebrated its first full calendar year with no indigenous cases of the disease. Systematic interventions began in 1992 and were gradually intensified until the final indigenous case occurred in July 2003. The favorable concentration of most cases in relatively few northern districts of the country was partly offset by chronic insecurity in much of the endemic area and by repeated importations of cases from neighboring Sudan. Strong support and dedicated leadership by government officials and external partners were keys to this program's dramatic success. This program cost approximately US\$5.6 million.
\end{abstract}

\section{INTRODUCTION}

Guinea worm disease (dracunculiasis) is transmitted when humans drink water, usually from stagnant ponds, containing tiny copepods that have ingested immature larvae of the parasite. The worms mature in about a year and emerge slowly and painfully, directly through the skin, on any part of the victim's body. When the emerging 2- to 3 -ft $(1 \mathrm{~m})$ worm is exposed to fresh water, it ejects hundreds of thousands of larvae into the water to continue the cycle. Infected persons may be incapacitated for 2-3 months by an emerging worm. There is no effective treatment or cure, and people do not become immune to infection. However, the infection can be prevented by teaching people at risk to filter their drinking water through a finely woven cloth, by educating victims to avoid entering a drinking water source when their worm(s) are emerging, by treating contaminated sources of water with ABATE (BASF AG, Ludwigshafen, Germany) larvicide, and by providing safe sources of drinking water (e.g., a borehole well). ${ }^{1}$

The first known documentation of dracunculiasis in Uganda was by Bamundaga, ${ }^{2}$ who described a case in a young man from West Nile District in 1934. Bradley ${ }^{3}$ found cases of the disease in the West Nile, Acholi, Moyo, and Nakasongola Districts in 1968. Other epidemiologic surveys in 1983, 1984, and 1988 revealed prevalent cases in the Kitgum, Kotido, and Moroto Districts. ${ }^{4-6}$ As in other endemic countries, dracunculiasis caused much suffering across northern Uganda. Victims could not tend their crops or cattle or care for children, and many children were unable to walk to school. Some children and adults were permanently deformed or crippled by the disease.

The global campaign to eradicate dracunculiasis began as an initiative of the US Centers for Disease Control (CDC) in 1980, under the auspices of the international Drinking Water Supply and Sanitation Decade (1981-1990). The World Health Assembly adopted the first resolution calling for the "elimination" of dracunculiasis in 1986 but set no deadline. Two years later, African ministers of health set a target date of 1995, which was confirmed by the World Health Assembly in 1991. In 2004, Ministers of Health of the remaining endemic countries and the World Health Assembly set a new target date of 2009 .

* Address correspondence to Donald R. Hopkins, The Carter Center, 453 Freedom Parkway, Atlanta, GA 30307. E-mail: sdsulli@emory.edu

\section{MATERIALS AND METHODS}

Initiation of the program. The Uganda Guinea Worm Eradication Program (UGWEP) was established by the Ministry of Health in 1991 in collaboration with The Carter Center (Global 2000) and the UNICEF Country Office, following a visit to Uganda by former US President Jimmy Carter in 1990, when he discussed the disease with President Yoweri Museveni and offered Carter Center assistance. The program conducted a village-by-village search for cases of dracunculiasis between October 1991 and July 1992. The searchers covered 17 suspected endemic districts in northern Uganda, with an estimated at risk population of $\sim 6.7$ million persons. The case search enumerated a total of 126,369 cases in 2,667 villages in 16 districts (Figure 1). Nearly $95 \%$ of the cases were located in only three contiguous districts (Kitgum, Kotido, Moroto) in northeastern Uganda, and 99\% of cases were found in only five districts (including Gulu and Arua). ${ }^{7,8}$

The peak transmission season for dracunculiasis in Uganda (April through July) was not known before monthly reporting of cases began in 1993. During a Knowledge-AttitudesPractices (KAP) study conducted in Kotido District in 1997, twice as many women as men suffered from dracunculiasis (S. McLaine, personal communication). When age and sex data were collected on patients routinely, a majority of cases were female (e.g., $59 \%$ of 1,455 cases in 1996 and $76 \%$ of 51 cases in 2001 , when $87 \%$ of those females were $11-40$ years old). This predominance of female victims in Uganda is probably a consequence of their role as the main gatherers of household water supplies. Such activity provides extra opportunities for drinking water directly from contaminated sites in addition to potentially filtered water that is consumed in the home by all members of the family. Most cases in Kotido and Moroto Districts were among the heavily armed nomadic nilotes, the Karamojong.

The Ministry of Health appointed a national coordinator and a national field officer, and The Carter Center assigned a full-time resident advisor to help establish and maintain the national secretariat for the Guinea Worm Eradication Program from 1991 through 1998. The secretariat oversaw the selection and training of national and district coordinating committees and district coordinators. The Carter Center also provided funding for operational support of the program, as well as nylon filter cloth (donated by DuPont Corporation, Wilmington, DE, and Precision Fabrics Group, Greensboro, NC) and ABATE larvicide (donated by American Cyanamid, Wayne, NJ, American Home Products, Madison, NJ, and 


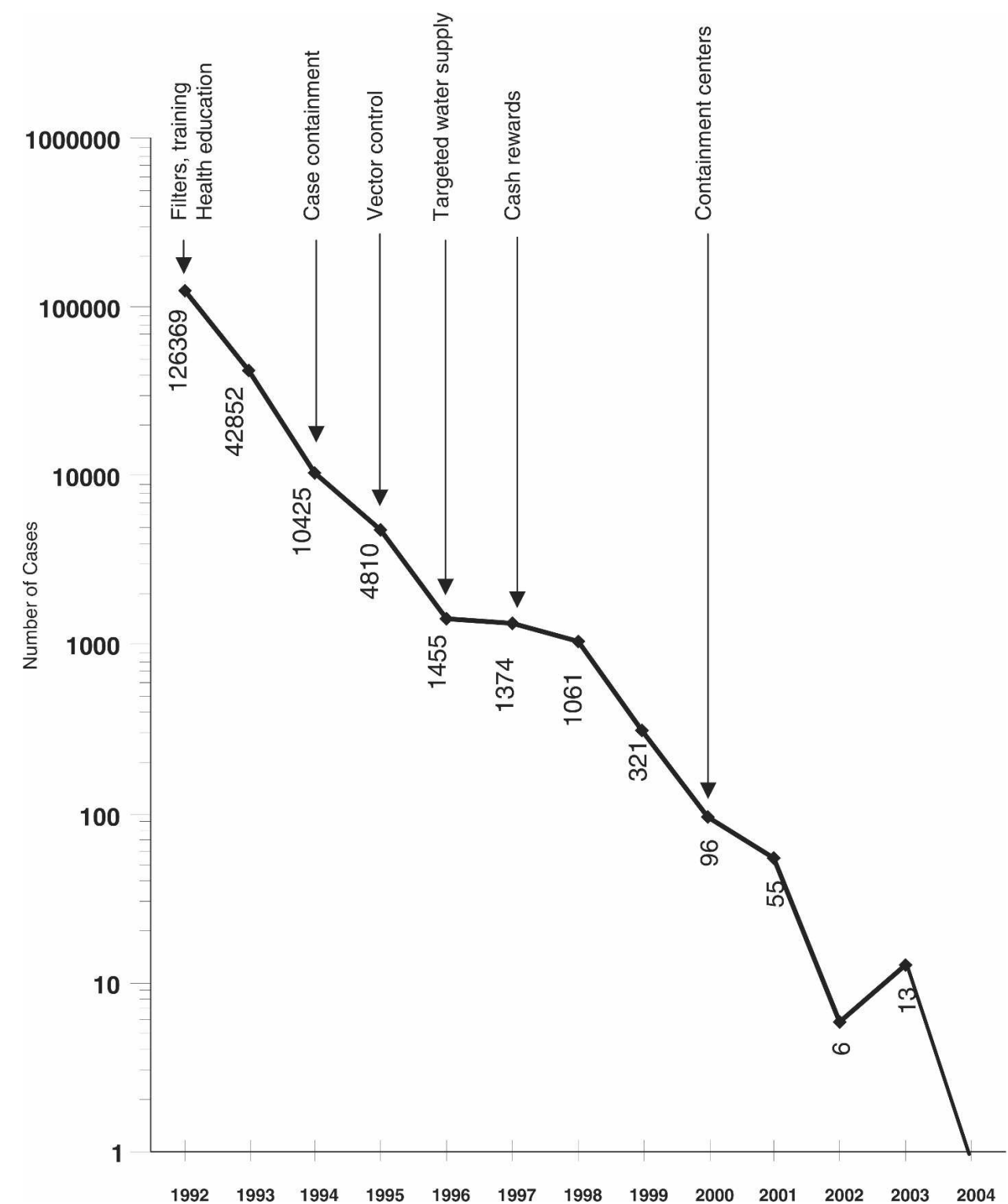

FIGURE 1. Number of cases of dracunculiasis reported since 1992 in Uganda and year of introduction of interventions and strategies.

BASF). UNICEF also provided operational support, rehabilitated wells, and new borehole wells. Sub-county and district level meetings of village volunteers and their supervisors were held monthly until 1999, and quarterly thereafter. The national task force, which met monthly, and district coordinating committees included representatives from ministries of health, education, local government, information, agriculture, women in development, and water development, as well as representatives of key bilateral and multi-lateral agencies and non-governmental organizations (NGOs). An annual national conference to review progress and make plans for the following year coincided with the annual National Guinea Worm Day.

A village or manyatta was considered as an operational unit: the smallest population unit in a local area for purposes of training, implementation of interventions, and surveillance. Initially all villages in the five most heavily endemic districts were considered to be endemic.
Interventions. Systematic interventions began after training courses that were held in Kitgum in May 1992 and in Kotido and Moroto Districts in July 1992. By the end of 1992, 84\% of the 2,677 selected village volunteers (1 per endemic village) had been trained, $76 \%$ were reporting cases monthly, and health education had been conducted in $91 \%$ of the endemic villages.

When the first national conference was held in June 1993, reports indicated that $96 \%$ of endemic villages had a trained volunteer, and $45 \%$ of them had distributed nylon filters. All endemic districts were asked to update the lists of endemic villages to focus activities in 1994 based on the number of cases reported in each village by month during 1993. Any village reporting zero cases throughout a calendar year would be considered non-endemic for the following year. The percentage of known endemic villages where nylon filters were distributed rose to $64 \%$ by the end of $1993,67 \%$ at the end of 1994, and $100 \%$ at the end of 1995 (Table 1). 
TABLE 1

Uganda Guinea Worm Eradication Program (GWEP)

\begin{tabular}{|c|c|c|c|c|c|c|c|c|c|c|c|c|c|c|c|}
\hline & Parameters & $1991 / 2$ & 1993 & 1994 & 1995 & 1996 & 1997 & 1998 & 1999 & 2000 & 2001 & 2002 & 2003 & 2004 & 2005 \\
\hline \multirow{3}{*}{$\begin{array}{l}\tilde{d} \\
\tilde{U} \\
\tilde{U}\end{array}$} & \# Indigenous & 126,369 & 42,852 & 10,425 & 4,810 & 1,455 & 1,374 & 1,061 & 321 & 92 & 55 & 6 & 13 & 0 & 0 \\
\hline & \# Imported & N/A & N/A & N/A & 13 & 7 & 0 & 162 & 5 & 4 & 4 & 18 & 13 & 4 & 9 \\
\hline & $\%$ of cases contained & $0 \%$ & $0 \%$ & $1 \%$ & $51 \%$ & $82 \%$ & $60 \%$ & $79 \%$ & $93 \%$ & $76 \%$ & $64 \%$ & $75 \%$ & $73 \%$ & $100 \%$ & $100 \%$ \\
\hline \multirow{6}{*}{ 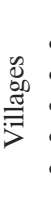 } & \# Endemic & 2,667 & 2,677 & 1,027 & 740 & 327 & 244 & 164 & 108 & 42 & 8 & 6 & 1 & 0 & 0 \\
\hline & $\%$ Reporting monthly & $76 \%$ & $70 \%$ & $91 \%$ & $95 \%$ & $99 \%$ & $99 \%$ & $100 \%$ & $100 \%$ & $100 \%$ & $100 \%$ & $100 \%$ & $100 \%$ & - & - \\
\hline & $\%$ Health education & $91 \%$ & $70 \%$ & $70 \%$ & $100 \%$ & $100 \%$ & $100 \%$ & $100 \%$ & $100 \%$ & $100 \%$ & $100 \%$ & $100 \%$ & $100 \%$ & $100 \%$ & $100 \%$ \\
\hline & $\%$ Nylon filters & $15 \%$ & $67 \%$ & $67 \%$ & $100 \%$ & $100 \%$ & $69 \%$ & $99 \%$ & $100 \%$ & $100 \%$ & $100 \%$ & $100 \%$ & $100 \%$ & - & - \\
\hline & $\%$ Vector control & $0 \%$ & $0 \%$ & $0 \%$ & $33 \%$ & $78 \%$ & $38 \%$ & $39 \%$ & $97 \%$ & $96 \%$ & $97 \%$ & $100 \%$ & $100 \%$ & - & - \\
\hline & $\begin{array}{l}\% \text { With one or more } \\
\text { sources of safe water }\end{array}$ & $9 \%$ & $33 \%$ & $37 \%$ & $45 \%$ & $45 \%$ & $46 \%$ & $65 \%$ & $65 \%$ & $65 \%$ & $83 \%$ & $67 \%$ & $100 \%$ & - & - \\
\hline
\end{tabular}

Training on case containment (prevention of transmission from individual patients) and use of ABATE larvicide for vector control was conducted for all members of district health teams in the endemic districts at the beginning of 1994. This and previous training were assisted by consultants provided by The Carter Center and CDC. All districts were to implement the case containment strategy and ABATE application in every endemic village by the end of 1994. Appropriate drinking water sources were identified and targeted for monthly treatment with ABATE in most endemic villages. At first, certain nomadic pastoralists (Karamojong) resisted application of ABATE in their water supplies out of suspicion that the government wanted to kill their cattle, but this resistance was overcome in most areas after intensive education and mobilization of and by local political, traditional, and opinion leaders in collaboration with the program. By the end of $1994,>95 \%$ of endemic villages were practicing case containment, and about one half of cases reported in January 1995 were fully contained. ABATE use was negligible in 1994 , but rose to $3 \%$ and $10 \%$ of endemic villages as of June and October 1995, respectively.

Targeted water supply efforts in endemic villages began in 1997, with the collaboration of the Ugandan Directorate of Water Development, UNICEF, and two NGOs: Water-Aid and AVSI (Associazione Voluntari per il Sevizio Internationale). Scores of endemic villages in the top three endemic districts benefited from provision of safe water sources like bore hole wells or protected hand dug wells starting that year, eventually reaching all remaining endemic villages toward the end of the program, as a result of an intensive push and support by the UNICEF country office.

A strategy to recruit Pond Care Takers to guard ponds against contamination by people with emerging worms evolved during an inter-district review meeting in Kotido in 1999. Elderly Karamojong men who were not able to herd cattle were asked to select one of their peers who would keep watch over the water source and prevent people with emerging worms from entering it. They also helped fetch water for elderly or sick persons, especially women with emerging worms, and they were given nylon filters to supply anyone who came to fetch water without a filter. Some of the Pond Care Takers built fences around the pond, and/or separated drinking points for cattle from those for humans, using local materials such as thorny shrubs.

To help improve the sensitivity of surveillance, a cash reward system for reporting of a case of dracunculiasis was introduced on a pilot basis in Kitgum District in mid-1997 and extended nationwide in 1999. In 1999, anyone who reported a case of dracunculiasis, and the patient him/herself, each received a reward of 10,000 Ugandan shillings ( $\sim$ US \$6), and the village volunteer who treated the case received 4,000 Ugandan shillings. The amount of the reward was increased to 20,000 Ugandan shillings in 2000, 50,000 shillings in 2001, and 100,000 shillings in 2002, where it remains. A sample survey conducted by a joint team from WHO and CDC as part of a WHO-sponsored pre-certification assessment in November 2005 , found that $90 \%$ and $81 \%$ of villagers queried in Kotido and Moroto Districts, but only 30\% of those in Arua District, knew of the cash reward (A. Tayeh and S. Roy, personal communication).

In 2000, the program began pilot testing another innovation by voluntarily institutionalizing patients with dracunculiasis in existing health facilities in Kotido District. All suspected cases with swellings and/or blisters were detected in their villages and urged to stay in the nearest public health clinic for management and case containment until their blisters burst, the Guinea worms emerged, and the worm was manually pulled out. The patients were provided free food and received the appropriate cash reward on completion of the containment process. Of the 13 patients who were contained during the first 9 months of 2002, 12 were physically isolated in such a health clinic.

Social mobilization and sensitization of the populations at risk, and of those who serve them, underlay all of the other interventions. This involved a variety of cadres from different ministries, NGOs, political leaders, administrators, traditional and religious leaders, and the village volunteers, and aimed to engender both individual and community participation. Several community sessions were held, using flip charts, videos, radio messages, etc. As mentioned above, intensive community education was required to reverse initial resistance to use of ABATE among some of the Karamojong.

Progress of the program and the impact of interventions were monitored regularly by comparing the reported monthly incidence to that of the same month the year before and by reviewing the reported coverage of known endemic villages by each intervention monthly. The sensitivity of surveillance was checked by investigation of sporadic cases and maintenance of "rumor registers" of false-positive reports. External reviews were conducted twice annually, during the intercountry meeting of representatives of all national Guinea Worm Eradication Programs each March and the Program Reviews that were held for smaller groupings of endemic countries each September or October. 


\section{RESULTS}

Costs. We estimate that this program cost about $\$ 5.6$ million between 1992 and 2004. The Carter Center provided approximately \$2.3 million between 1992 and 2004, with annual expenditures of just under $\$ 300,000$ through 1998, when Carter Center funding for Uganda dropped to about $\$ 50,000$ per year after the continued presence of a full-time resident technical advisor and more extensive operations were deemed to no longer be necessary. The annual budget of the entire UGWEP (including Carter Center support) was about $\$ 400,000$ in 1998 and in 2000 , but rose to $\$ 853,000$ in 2001 to include additional expenditures by UNICEF for improved drinking water supply in endemic villages, and fell to $\$ 285,000$ in 2002. In 2001, the breakdown of support was $\$ 740,000$ (UNICEF), \$64,000 (Carter Center), \$25,000 (World Health Organization [WHO]), \$20,000 (Government of Uganda, in addition to staff salaries), and \$6,200 (Health and Development International [HDI]). UNICEF also provided \$1 million for water supply improvements in 1996-1997. The WHO provided modest support of $\$ 25,000-\$ 50,000$ per year in 2001 2004, and HDI also supported rewards for reporting of cases and for the national headquarters of the program in the latter years $(\$ 6,200$ in $2001, \$ 10,000$ in 2002 , and $\$ 15,200$ in 2003). UNICEF and the United Nations Development Program provided small but important funding at the beginning of the program for conducting the national search and preparing the national Plan of Action, respectively.

Impact. The results of the Ugandan program's interventions are shown in Figures 1 and 2. From $>126,000$ cases enumerated during the national case search in 1991-1992 and nearly 43,000 cases reported in 1993, when only Nigeria reported more cases $(75,752)$, the annual number of indigenous dracunculiasis cases reported in Uganda declined steadily except for a brief pause in 1996-1997 and a slight increase in 2003. This is an average annual reduction of $46 \%$ in the number of cases over the 12 years until zero indigenous cases were reported for the first time in 2004. The number of endemic villages and affected geographic areas paralleled that decline. The program experienced a small setback in 2001, when an outbreak of 43 cases was discovered in Rikitae village in the Kotido District. This village had (under-)reported only five cases in 2000, which was reduced to three cases in 2002. Uganda's last indigenous case was a 58-year-old man in Nawaupoet village of the Kotido District whose worm began emerging on July 14, 2003.

The 239 imported cases that were documented between 1995 and 2005 show the recurrent danger of imported cases from Sudan (Table 1). An external independent evaluation conducted by WHO in November 2005 confirmed the interruption of transmission of dracunculiasis in Uganda (A. Tayeh and S. Roy, personal communication).

\section{DISCUSSION}

The UGWEP's stunning success will not be matched by any other country, because each of the other highly endemic countries' national programs have already experienced major delays (since overcome) for various reasons, from Sudan's long-lasting civil war to serious ethnic clashes and inadequate funding in Ghana and Nigeria. Uganda's success in a region of the country that experienced the worst insecurity in the late 1970s, coupled with a deteriorating economy, terror, socioeconomic and political disruption, and the breakdown of virtually every civil system, ${ }^{9}$ is thus all the more remarkable. That this was also achieved despite numerous unpredictable importations of cases from Sudan is almost unbelievable. Fortunately, the latter threat is diminished as Sudan's GWEP reduces the number of cases in that country. ${ }^{10}$

Although the original target date for eradicating dracunculiasis from Uganda was 1995, this could not be achieved because of the prolonged civil conflicts in the endemic districts, including deadly raids by rebels of the so-called Lord's Resistance Army (LRA), operating from southern Sudan. Training in use of ABATE larvicide and for case containment was delayed for months partly because of insecurity in the endemic areas. The dramatic upsurge in cases imported from Sudan in 1998 probably reflected turmoil and a major assault by competing Sudanese rebel groups and the famine that resulted from that turmoil, with consequent increased migration of fleeing civilians. ${ }^{11}$

Before 10,000 Ugandan soldiers were sent into Sudan (under an agreement with Sudanese authorities) in pursuit of the LRA in 2002, they were educated about dracunculiasis and had portable pipe filters for filtering their drinking water in the field included in their supplies (Figure 3). Several program personnel were killed while conducting active surveillance for dracunculiasis in their villages. A district team leader was abducted and held captive for several weeks in 1997. However, in 1999, progress made in the UGWEP facilitated Carter Center mediation among the governments of Uganda and Sudan, the LRA, and the Sudan Peoples' Liberation Movement that resulted in restoration of diplomatic relations between Uganda and Sudan.

During the course of the campaign to eradicate dracunculiasis, there has never been a single incident of human toxicity related to the use of ABATE larvicide (Temephos), including during the eradication campaign in Uganda. The ABATE larvicide formulation for GWEPs is the $50 \%$ emulsifiable concentrate, and the standard dose used for control of copepod populations in stagnant sources of drinking water is one part per million, as recommended by the WHO Expert Committee on Insecticides. ${ }^{12}$ Assurance of safety of use of ABATE larvicide in actual or potential sources of drinking water is a function of the thorough training of ABATE larvicide application teams, adherence to the CDC Guidelines for Chemical Control of Copepod Populations in Dracunculiasis Eradication Programs, and the experience of ABATE larvicide application cadres in its use.

How did Uganda do it? Innovations, as shown by testing and adoption of strategies such as the Pond Care Takers, case containment centers, and cash rewards for reporting of cases were part of the answer, but no one innovation or intervention was responsible for Uganda's success. Other important factors include the program's early decision to distinguish between endemic and non-endemic villages and focus intensively on the former for targeting health education, filter distribution, and application of ABATE larvicide, as well as the relentless increase in the intensity, quality, and number of interventions as the program progressed. This program was never distracted by arguments about vertical or horizontal implementation strategy, but resolved to do whatever was required to eradicate dracunculiasis. 


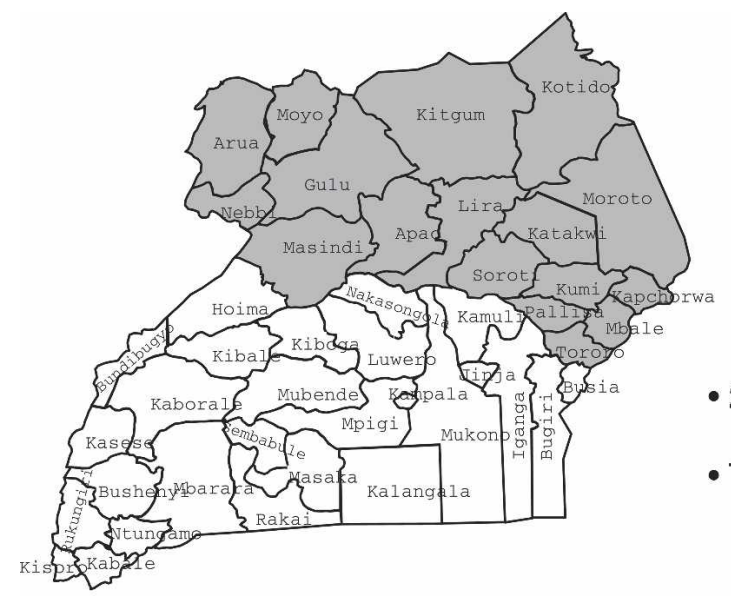

-2, 677 endemic villages in 16 districts

- Total of 126,369 cases reported

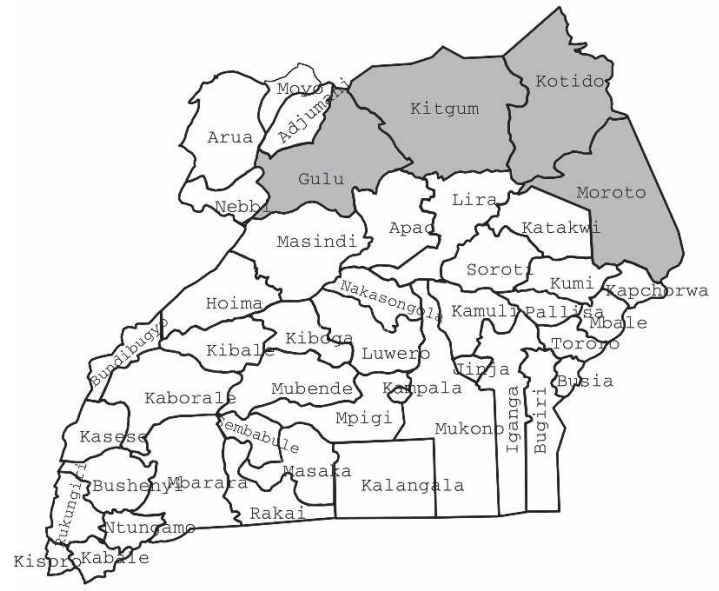

1997

- 327 endemic villages in 4 districts

- Total of 1,455 cases reported

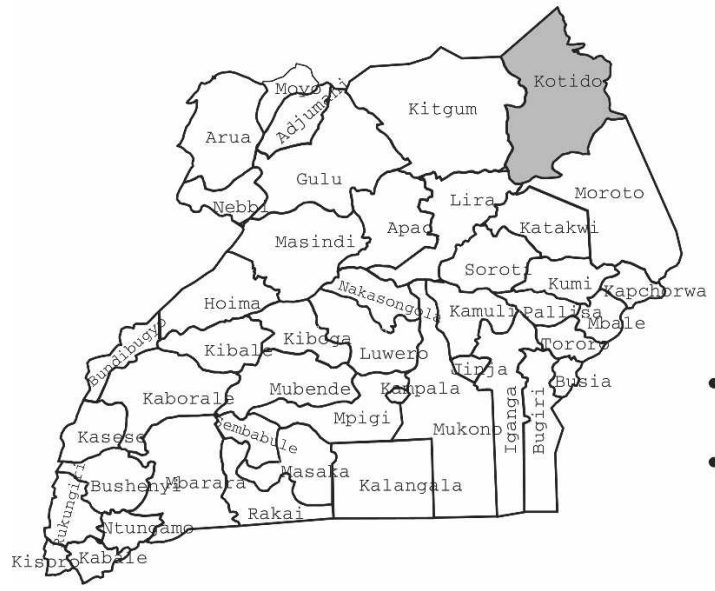

\section{3}

- 1 endemic village in 1 district

- Total of 13 cases reported

FIGURE 2. Distribution of Guinea Worm disease in Uganda.

Perhaps the most important factors in Uganda's success, however, were the sustained support of the program by the Government of Uganda, including strong leadership provided by ministry of health officials, and the support provided by external agencies and donors. Support by the government was manifest in numerous ways, including high-level participation in the annual National Guinea Worm Conference (the vicepresident, minister of foreign affairs, prime minister, minister or state minister of health in different years) and designation of the program as a priority in the national 5-year plan in 1999. The president of Uganda cited the success of the
UGWEP in appealing for votes in northern Uganda during his campaign for re-election in 2001. The program's leaders practiced hands-on supervision, including spot checks, and promptly replaced health workers who performed poorly. The Carter Center and the UNICEF mission to Uganda were the major external supporters of the program, with additional external support provided by two Italian NGOs (Associazione Voluntari per il Sevizio Internationale and Collegio Universitario Aspirante Medici Missionari), the Centers for Disease Control and Prevention, the governments of Canada, Denmark, Japan, Kuwait, Norway, Oman, Saudi Arabia, 


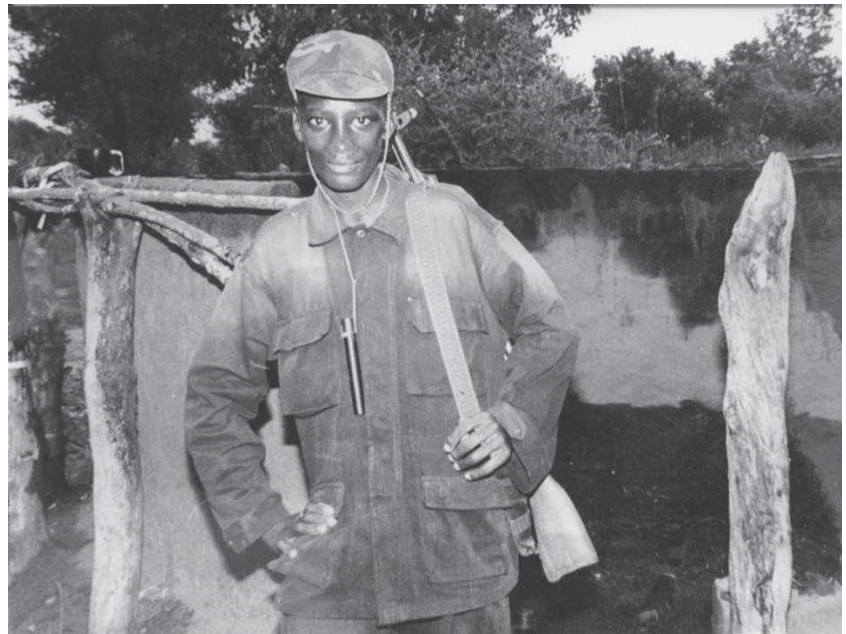

FIGURE 3. Ugandan soldier with pipe filter to prevent infection with Guinea worm disease (photo by John Nsimbe from The Monitor-Kampala).

Sweden, United Arab Emirates, and the United States, the Japanese businessmen's consortium Keidanren, HDI, the Bill and Melinda Gates Foundation, and the WHO.

It is impossible to determine the accuracy of the original estimate of cases enumerated by the national case search in 1991-1992. The sharp reduction of cases reported once monthly reporting of fresh cases began in 1993, and knowledge that some of the cases enumerated in the national search were retrospective historical cases that reportedly had occurred over the past 12 months suggests that over-reporting may have outweighed any under-reporting during the search. However, health education and distribution of nylon filters also began in some areas even before the case search ended, and the rate of reduction of cases was even greater between 1993 and 1994 than it was between the case search and 1993, so the original estimate in this instance may well have reflected the actual situation closely.

The UGWEP has maintained sensitive surveillance for dracunculiasis in the 2.5 years since indigenous transmission was interrupted. This surveillance system promptly detected and contained four imported cases in 2004 and nine imported cases in 2005. In addition, at least nine suspected cases were studied in 2005 and found not to be cases of dracunculiasis. The program continues to publicize the cash reward for reporting of a case and conducts spot checks of the level of awareness about the reward. Active surveillance for dracunculiasis is also still conducted in the areas of the country believed to be at highest risk of imported cases. The program will need to maintain this level of vigilance until dracunculiasis is also eliminated from southern Sudan, and in order to meet WHO's criteria for official certification of eradication.

Received February 2, 2006. Accepted for publication March 10, 2006.
Acknowledgments: The program is greatly indebted to the late Dr Gilbert Mpigika (former program manager) and the late John Okidi (former national field coordinator) for hard work, and we salute the brave village volunteers, other community health workers, subcounty supervisors and district coordinators and health teams, some of whom lost their lives in the process, the field commander Den W.O. Ongwen, data manager David Ngira, administrator Paula Turyahikayo, recent program manager Dr. Peter Langi, and all other support staff of the UGWEP. We also acknowledge with gratitude the dedicated support of various staff and country representatives of The Carter Center (especially Elvin Hilyer and Mark Pelletier), the UNICEF country office (especially Kathleen Cravero, Lloyd Donaldson, Bill Fellows, and Sebunya-Kiwa), CDC, and WHO (especially Drs. Josephine Namboze, Alhousseini Maiga, and Ahmed Tayeh), including several consultants (especially the late Larry Dodd and Karl Kappus) and Dr. Anders Seim of HDI, who assisted the program. The authors thank Rosalyn Ajigbeda, Renn McClintic-Doyle, and Shandal Sullivan, who helped prepare the manuscript for publication.

Fianncial support: In 2005, The Carter Center's work to eradicate Guinea worm was made possible by financial and in-kind contributions from the Bill and Melinda Gates Foundation, Conrad N. Hilton Foundation, Canadian International Development Agency, AG Leventis Foundation, United States Agency for International Development, US Centers for Disease Control \& Prevention, OPEC Fund, Salus Mundi Foundation, Vestergaard Frandsen, BASF Corporation, many private donors, and the governments of Japan, Kuwait, Norway, Oman, and Saudi Arabia.

Authors' addresses: John B. Rwakimari, National Malaria Control Programme, Ministry of Health, Loudel Road, PO Box 7272, Kampala, Uganda, Telephone: 25677461 942, Fax: 25641231 603, E-mail: dr_jbr@yahoo.com. Ernesto Ruiz-Tiben and Donald R. Hopkins, Guinea Worm Eradication Program, The Carter Center, 453 Freedom Parkway, Atlanta, GA 30307, Telephone: 770-488-4509, Fax: 770-488-4532; E-mails: exr1@cdc.gov and sdsulli@emory.edu.

\section{REFERENCES}

1. Hopkins DR, Ruiz-Tiben E, 1991. Strategies for eradication of dracunculiasis. Bull World Health Organ 69: 533-540.

2. Bamundaga DA, 1934. A case of Guinea worm. E Afr Med J 11: 292.

3. Bradley DJ, 1968. Disease Map of Uganda. Entebbe: Ministry of Health.

4. World Health Organization, 1984. Dracunculiasis surveillance: Uganda. Wkly Epidemiol Rec 59: 69-71.

5. Bukenya G, 1987. A survey of dracunculiasis in Chua County, Kitgum District of Uganda. E Afr Med J 64: 102-107.

6. Henderson PL, Fontaine RE, Kyeyune G, 1988. Guinea worm disease in northern Uganda: a major public health problem controllable through an effective water program. Int J Epidemiol 17: 434-440.

7. World Health Organization, 1993. Dracunculiasis eradication. Update: 1992, Uganda. Wkly Epidemiol Rec 68: 81-83.

8. World Health Organization, 1995. Dracunculiasis eradication. Update; 1993-1994, Uganda. Wkly Epidemiol Rec 70: 161-162.

9. Dodge CP, Weibe PD, eds., 1985. Crisis in Uganda: The Breakdown of Health Services. New York: Pergamon Press.

10. Hopkins DR, Ruiz-Tiben E, Downs P, Withers PC Jr, Maguire JH, 2005. Dracunculiasis eradication: the final inch. Am J Trop Med Hyg 73: 669-675.

11. Johnson DH, 2003. The Root Causes of Sudan's Civil Wars. Indianapolis, IN: Indiana University Press.

12. World Health Organization, 1973. Safe Use of Pesticides. Twentieth Report of WHO Expert Committee on Insecticides. Geneva, Switzerland: World Health Organization. 